\title{
ANNIVERSARIES
}

This year, several National Societies have celebrated the anniversary of the date when they were founded:

- 125 years (1866): Swiss Red Cross;

- 70 years (1921): Albanian Red Cross;

- 60 years (1931): New Zealand Red Cross;

- 30 years (1961): Burkinabé Red Cross;

- 25 years (1966): Gambia Red Cross;

Kuwait Red Crescent;

- 20 years (1971): Fiji Red Cross;

Mauritanian Red Crescent;

- 10 years (1981): Red Cross of Grenada;

Qatar Red Crescent;

Zimbabwe Red Cross.

Likewise, the Hungarian Red Cross, which hosted the Movement's international statutory meetings, is celebrating 110 years of existence. This year is also the 110th anniversary of the American Red Cross.

The Review warmly congratulates these National Societies and expresses its best wishes for the success of their future activities.

\section{Recognition of the Lithuanian Red Cross Society confirmed}

At its Assembly on 7 November 1991 the International Committee of the Red Cross confirmed the validity of its previous recognition, on 28 August 1923, of the Lithuanian Red Cross Society. 
This decision, which enables the Lithuanian Red Cross Socicty to resume its place within the International Red Cross and Red Crescent Movement. brings the number of duly recognized National Societies to 149.

\section{Recognition of the Latvian Red Cross Society confirmed}

The International Committee of the Red Cross confirmed on 20 November 1991 the validity of its recognition of the Latvian Red Cross Society announced on 10 January 1923.

This decision, which enables the Latvian Red Cross to resume its place in the International Red Cross and Red Crescent Movement, brings to $\mathbf{1 5 0}$ the number of duly recognized National Societies. 